\title{
COMPREHENSIVE EVALUATION OF EXPRESSION PLATFORM: CHERRY PICKING THE 'RIGHT' TO ACCOMPLISH THE 'BEST'
}

\author{
Shailendra Gaur \\ Kinjal Bhadresha \\ Baldev Patel \\ Meenu Saraf \\ Rakesh Rawal
}

\section{Abstract}

Mounting demands for biosimilars and continuous emphasis on cost reduction of drugs have motivated researchers across the globe to widen the horizon of screening in $\mathrm{CHO}$ cells based bio-production. Various groups have exploited multiple phenomena in $\mathrm{CHO}$ cells for better expression and improved quality of therapeutic protein, for example use of transposons, regulatory elements, engineering of cell lines for site specific integrations or knock-in/knockout models to achieve the desired results. The current study presents the data for evaluation of three mammalian expression platforms available in market having three different approaches for improving productivity. One, the MTX based platforms for gene amplification,

GS knock-down based selectionsystem and UCOE based active transcription system. To evaluate the platforms stringently, stable pools of both $\mathrm{mAb}$ and non-mAb molecules were accessed. Our results suggested that UCOE based platform have performed exceedingly well in monoclonal antibody (mAb) expression in comparison to the other two platforms. Whereas, for non mAb molecules, UCOE based platform was comparable to other two platforms. On 
Towards Excellence: An Indexed, Refereed \& Peer Reviewed Journal of Higher Education /

Shailendra Gaur, Kinjal Bhadresha, Baldev Patel, Meenu Saraf, Rakesh Rawal / Page 143-165

evaluating all the molecules, CHOGS (-) system was found least productive as compared to the other two platforms in almost all cases.

Keywords: expression, therapeutic proteins, evaluation, DHFR, GS, recombinant, UCOE

\section{Introduction}

1. $\mathrm{CHO}$ and platform technologies:

Recombinant therapeutic proteins have emerged as the next generation of pharmaceutical treatments. The billion-dollar protein drug industry is expected to grow by leaps and bounds due to increasing demand and identification of newer targets and drug products. It has been predicted that by 2020 almost $50 \%$ of the blockbuster drugs will be biologics (Pohlscheidt et al. 2018). Although both microbial and mammalian platforms have been used to produce these protein drugs, mammalian cell lines like $\mathrm{CHO}, \mathrm{BHK}-21$ and $\mathrm{HEK}-293$ have been a popular choice due to the complexity of post-translational modifications of these proteins (Kim et al. 2012; Xu et al. 2015; Luchese et al. 2018).

The huge market of these recombinant proteins has generated the need for faster, higher and better product development. The focus of research has thus shifted to improving efficiencies and yields without compromising on product quality. Extensive research on cellline, genome engineering, vector and bioprocess has led to an improvement in the production of recombinant proteins (Lazar et al. 2006; Kim et al. 2012; Butler and Meneses-Acosta 2012; Fischer et al. 2015; Buchsteiner et al. 2018). Numerous commercial organizations have combined the research from cell-line to bioprocess into saleable platform technologies (Gupta and Shukla 2017; Jazayeri et al. 2018; Tripathi and Shrivastava 2019). Development of platform technologies has enabled consistent and faster product development from these "biological workhorses". The discovery of genome editing tools has further explored the 
Towards Excellence: An Indexed, Refereed \& Peer Reviewed Journal of Higher Education /

Shailendra Gaur, Kinjal Bhadresha, Baldev Patel, Meenu Saraf, Rakesh Rawal / Page 143-165

possibilities of genomic engineering of cells to obtain the desired yields or post-translational modifications (Naso et al. 2010; Carroll 2011; Fischer et al. 2015; Siew 2016).

Optimization of cell-line, transfection strategy, optimizing media and feed combinations often take up valuable time and require large capital investment. The need for a quick solution in order to reduce timelines and increase cost-effectiveness has led to the need for outsourcing such activities. A few Service providers have stepped up to create platform technologies which often provide a complete cell-line development solution from vectors, cell-line to media and feed optimization. The service providers and the biopharmaceutical industry now work together on bringing these biologics to the market in a more efficient, cost effective and timely manner. In the recent years numerous service providers have come up with innovative platform technologies to aid cell-line development (Birch and Racher 2006; Lai et al. 2013). However, it is often challenging for a Biopharmaceutical manufacturer to pick one technology out of all the available technologies (Table 1) for their purpose. Multiple factors such as cell-line, vector system, titer, specific productivity, post-translational modifications, scalability concerns and lab conditions would influence the choice of technology by the manufacturer. Another major factor is the licensing and royalty requirements from technology providers that determine the choice of technology but is not being discussed in the article for obvious conflict of interest reasons. Also not considered is the time taken for completion of each technology evaluated and the quality profile for the molecules.

\section{Table 1: Commercially available mammalian expression technologies}




\begin{tabular}{|c|c|c|c|c|c|}
\hline \multicolumn{2}{|c|}{ Sr NProvider } & System & Cell-line & Vector & Technology Brief \\
\hline 1 & Invitrogen & $\begin{array}{l}\text { Freedom } \mathrm{CHO}- \\
\mathrm{S}\end{array}$ & CHO-S & pCHO 1.0 & $\begin{array}{l}\text { DHFR based technology. } \\
\text { Amplification possible by } \\
\text { addition of MTX }\end{array}$ \\
\hline 2 & Millipore & UCOE & $\mathrm{CHO}$ & Multiple & $\begin{array}{l}\text { Use of UCOEs element, } \\
\text { which augment gene } \\
\text { expression by sustaining the } \\
\text { chromatin in an "open" } \\
\text { configuration }\end{array}$ \\
\hline 3 & Sigma & $\mathrm{CHOZn} \mathrm{GS}^{-}$ & $\begin{array}{l}\text { CHOZn GS } \\
\text { line }\end{array}$ & pCGS3 & $\begin{array}{l}\text { GS knock down cells. } \\
\text { Amplification possible by } \\
\text { addition of MSX }\end{array}$ \\
\hline 4 & Lonza & GS Xceed & CHOK1SV-GS-KO & Multiple & $\begin{array}{l}\text { GS based technology. } \\
\text { Amplification not needed }\end{array}$ \\
\hline 5 & Horizon & CHO SOURCE & GS null CHOK1 & Multiple & $\begin{array}{l}\text { GS based technology. } \\
\text { Amplification possible by } \\
\text { addition of MSX }\end{array}$ \\
\hline 6 & $\begin{array}{l}\text { Edinburgh } \\
\text { Innovations }\end{array}$ & OSCAR & $\begin{array}{l}\text { HPRT deficient } \\
\text { mammalian cells }\end{array}$ & $\begin{array}{l}\text { Partially } \\
\text { disabled HPRT } \\
\text { minigene } \\
\text { vectors }\end{array}$ & $\begin{array}{l}\text { HPRT deficient cell line is } \\
\text { transfected with partially } \\
\text { disabled HPRT minigene } \\
\text { vector containing gene of } \\
\text { interest. Defective enzyme } \\
\text { leads to amplification of } \\
\text { gene. }\end{array}$ \\
\hline 7 & NRC-CNRC & $\mathrm{CHO} \mathrm{BRI}^{-}$ & $\mathrm{CHO}{ }^{\mathrm{BRI}}$ cell line & pTT vectors & $\begin{array}{l}\text { Cumate switch enabled } \\
\text { vector system containing } \\
\text { S/MAR genetic element }\end{array}$ \\
\hline 8 & $\begin{array}{l}\text { Sartorius } \\
\text { Stedim }\end{array}$ & CellcaCHO & CHO DG44 & $\begin{array}{l}\text { DHFR vector } \\
\text { containing } \\
\text { S/MAR element }\end{array}$ & $\begin{array}{l}\text { DHFR based vector } \\
\text { technology. Amplification by } \\
\text { MTX is not required. }\end{array}$ \\
\hline 9 & Selexis & $\begin{array}{l}\text { Selexis } \\
\text { SGE/SUREtech } \\
\text { vectors }\end{array}$ & $\begin{array}{l}\text { CHO-M cell line } \\
\text { derived from } \mathrm{CHO} \\
-\mathrm{K} 1\end{array}$ & $\begin{array}{l}\text { SUREtech } \\
\text { vectors }\end{array}$ & $\begin{array}{l}\text { Epigenetic elements-based } \\
\text { vector system }\end{array}$ \\
\hline 10 & Crucell & $\begin{array}{l}\text { STAR } \\
\text { technology }\end{array}$ & PER.C6 and $\mathrm{CHO}$ & $\begin{array}{l}\text { STAR element } \\
\text { based vector }\end{array}$ & $\begin{array}{l}\text { STAR genetic element-based } \\
\text { vector system }\end{array}$ \\
\hline
\end{tabular}


Towards Excellence: An Indexed, Refereed \& Peer Reviewed Journal of Higher Education /

Shailendra Gaur, Kinjal Bhadresha, Baldev Patel, Meenu Saraf, Rakesh Rawal / Page 143-165

In the current study we have compared three such platform technologies to identify a platform technology that can be used for expression of multiple proteins with high yield. The study involved evaluation of three different mammalian expression platform technologies, working on three different principles. First one works on dihydrfolate reductase gene amplification technology. Second works on an insulator based technology where ubiquitous chromatin opening element was used for better transcription. And lastly a glutathione synthetase selection and amplification based technology. This is an unbiased research work and we do not want to point out specific technology names thus, in this study we will call them Technology-1, Technology-2, and Technology-3 respectively. And as this is a comparative study we will consider Technology-1 as control and will compare other technologies against it.

Technology-1: This platform was developed for expression of proteins in $\mathrm{CHO}$ based suspension cell line which has been adapted to attain high cell densities in serum-free suspension culture. This platform consists of a dihydrofolate reductase (DHFR) based system for cloning and expression of proteins of interest. DHFR enzyme converts dihydrofolate to active tetrahydrofolate which acts as a co-factor in the biosynthesis of amino-acids and nucleic acids. MTX or methotrexate competitively binds and inhibits DHFR. CHO shows basal level of DHFR activity. The vector system (vector-1) was developed in a way to contain both DHFR and puromycin as mammalian selection marker. Hence transfected $\mathrm{CHO}$ cells can be selected using puromycin and amplified for better yields using MTX.

Technology-2: This technology exploits the integration independent transgene expression ability of the UCOE (Ubiquitous Chromatin Opening Element) element. Insertion of transgene into the chromosome is often a random event leading to variable results. When a transgene is inserted in the heterochromatin region of the chromosome it may lead to its non-expression even if it carries a strong promoter (Neville et al. 2017). UCOE genetic element helps in opening up the chromatin which leads to consistent, site-of-integration independent expression of 
Towards Excellence: An Indexed, Refereed \& Peer Reviewed Journal of Higher Education /

Shailendra Gaur, Kinjal Bhadresha, Baldev Patel, Meenu Saraf, Rakesh Rawal / Page 143-165

transgene which follows it. UCOE element is also resistant to methylation, hence conferring stability to the integrated transgene (Zhang et al. 2010; Pfaff et al. 2013; Rocha-Pizaña et al. 2017; Romanova and Noll 2018). The UCOE based vector technology hence helps in higher and stable expression of proteins which is often based on the copy number of the inserted genes (Dharshanan et al. 2014; Neville et al. 2017). The expression vector (vector-2) apart from UCOE insulator, contains puromycin as selection marker.

Technology-3: This technology is based on the GS knockout system. Both the alleles of GS are knocked out using an advance artificial restriction enzyme. This platform consists of the CHO GS-/- cell line and a vector consist of active GS gene. Glutamine synthetase enzyme catalyses the conversion of glutamate to glutamine. Hence, a double knockout cell line for GS enzyme is auxotrophic for Glutamine. The vector (vector-3) supplements the GS gene required for survival in glutamine-free medium post transfection. Hence, only the cells containing the vector survive when they are subjected to glutamine free medium (Kalwy et al. 2000; Fan et al. 2012; Lin et al. 2019). The system is expected to reduce timelines since the cells do not need to undergo a cycle of amplification for higher yields although this may be possible using MSX (L-Methionine sulfoximine).

In this study we compared all three technologies using two monoclonal antibodies (Mab-1 and Mab-2) and two hormones (Non-Mab-1 and Non-Mab-2). Titer is the sole criteria that we selected for comparing the technologies at stable pool stage as in competitive biosimilar market, we can survive if we produce affordable drugs and titer plays most important part in making it affordable.

\section{Materials and methods}


Towards Excellence: An Indexed, Refereed \& Peer Reviewed Journal of Higher Education / Shailendra Gaur, Kinjal Bhadresha, Baldev Patel, Meenu Saraf, Rakesh Rawal / Page 143-165

Construction of expression vectors: The synthesis of codon-optimized sequences coding for the mAb and non-mAb molecules were outsourced. The coding sequences were received in cloning vector. The desired sequences were sub-cloned into vector-1, vector-2 and vector3 using the respective restriction enzymes. Appropriate restriction sites were inserted using specially designed primers wherever the desired restriction sites for sub-cloning were absent. The final clones were verified by Sanger sequencing using gene specific primers. Maxiprep was performed using the Endo-free plasmid Maxi kit (Qiagen, 12362) using manufacturers recommendations to generate plasmid DNA for transfections.

The experimental strategy can be summarized in a flow chart as shown below:

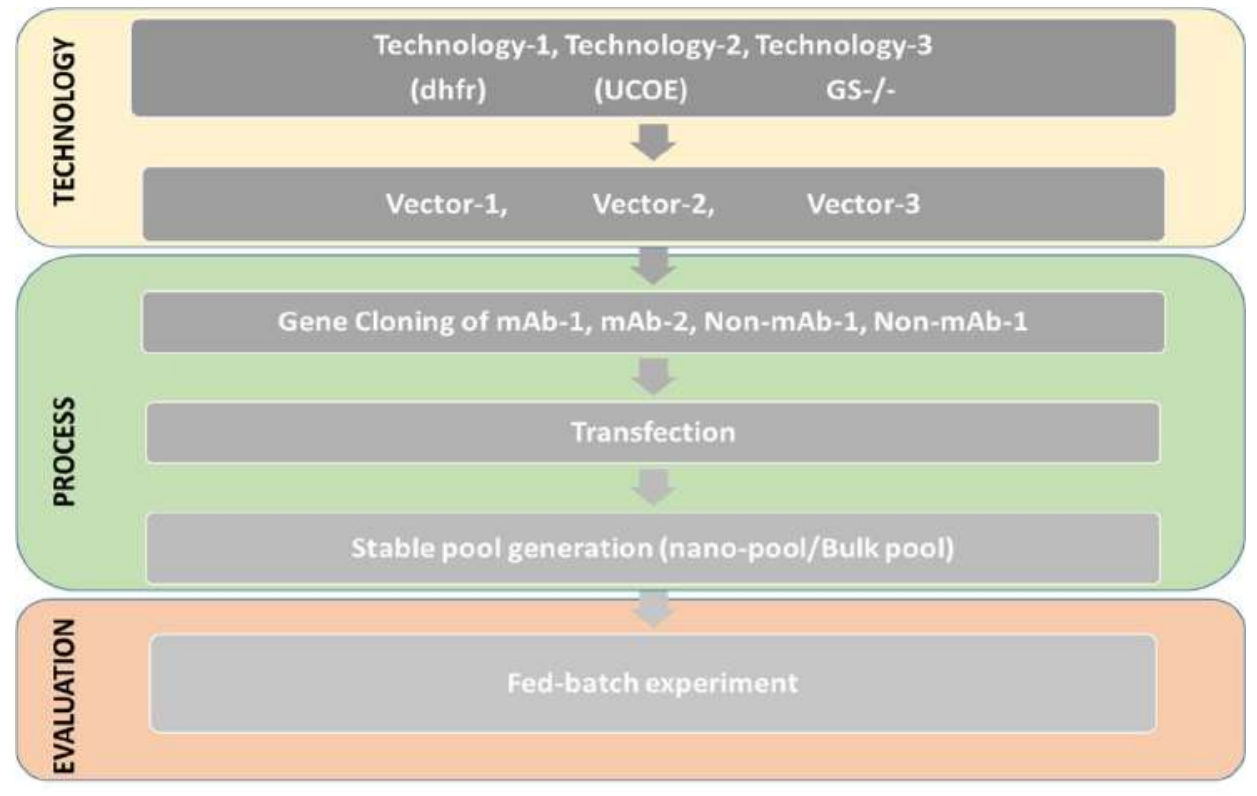

Figure 1: Schematic view of the experimental strategy used for evaluation of technologies

Transfection: For technology-1 and technology-2 lipofection based methods were recommended by the vendor thus FreeStyle max (Thermo, 16447100) was used. While for technology-3 electroporation method was recommended hence electroporation was used a as a method of vector delivery. 
Towards Excellence: An Indexed, Refereed \& Peer Reviewed Journal of Higher Education / Shailendra Gaur, Kinjal Bhadresha, Baldev Patel, Meenu Saraf, Rakesh Rawal / Page 143-165

Lipofection was performed as per the recommended protocol by Invitrogen. For $15 \times 10^{6}$ cells, $30 \mu \mathrm{g}$ DNA was used in 1:2 ratio with the lipofection reagent. Lipofection was performed in CD FortiCHO (Gibco, A11483-01) medium supplemented with $8 \mathrm{mM}$ glutamine (Sigma, G8540).

Electroporation was performed using Biorad Gene Pulser Xcell using parameters as mentioned in Table 2

Table 2: Electroporation conditions used for transfection

\begin{tabular}{|l|l|}
\hline Parameter & Set Value \\
\hline DNA/reaction & $30 \mu \mathrm{g}$ \\
\hline Total number of cells & $15 \times 10^{6}$ \\
\hline Electroporation buffer & PBS \\
\hline Type & Exponential decay \\
\hline Voltage & $300 \mathrm{~V} / 350 \mathrm{~V}$ \\
\hline Capacitance & $950 / 1100 \mu \mathrm{F}$ \\
\hline Cuvette size & $4 \mathrm{~mm}$ \\
\hline
\end{tabular}

Nano-pool generation: mAb1 was evaluated at a bulk pool stage since this was the first molecule chosen for technology evaluation. The results obtained with this molecule were studied and it was decided to evaluate other molecules at nono-pool stage. Post 48 hours of transfection, cells were seeded at a concentration of 5000-10000 cells/well (for nano-pools) and $0.5 \times 10^{6}$ cells $/ \mathrm{mL}$ in $25 \mathrm{~mL}$ media (for bulk pool) and subjected to appropriate pressure of Puromycin (Gibco, A1113802) and MTX (Sigma, 8407) for Vector-1, Puromycin for Vector-2 and medium without glutamine for Vector-3. Two to five 96-well plates were seeded for each 
Towards Excellence: An Indexed, Refereed \& Peer Reviewed Journal of Higher Education /

Shailendra Gaur, Kinjal Bhadresha, Baldev Patel, Meenu Saraf, Rakesh Rawal / Page 143-165

project to generate nano-pools. Puromycin concentration of 10 or $20 \mu \mathrm{g} / \mathrm{mL}$ and MTX concentration of 100 or $200 \mathrm{nM}$ was used for bulk and nano-pool generation for all molecules.

Screening of nano-pools: Screening of nano-pools was performed at various stages to narrow down to the top nano-pools which were then evaluated across all 3 technologies, as shown in figure 2. Screening was performed with either sandwich ELISA or dot blot. Standard procedure for ELISA and dot blot was performed using appropriate primary and secondary antibodies according to the molecules to be detected. A batch experiment was performed at 6 well plate or T25 flask stage for each technology and top 2 nano-pools were thus selected for fed-batch studies.

Fed batch experiment: A fed batch experiment was initiated according to the protocols recommended by the respective technology provider while evaluating technologies for mAb1. Since it was difficult to run different feeding schedules for different technologies, it was decided to adapt all cells to one medium and perform a fed batch using one single protocol. Cells were seeded at $0.5 \times 10^{6}$ cells $/ \mathrm{ml}$ and fed batch was run for 16 days or till the viability was maintained above $60 \%$ with intermittent feeding. Non-mAb2 was a sensitive molecule prone to degradation, hence we decided to shorten the run time for the fed-batch to 7 days with higher initial seeding density $\left(1 \times 10^{6}\right.$ cells $\left./ \mathrm{mL}\right)$.

\section{Results}

Construction of expression vectors: The codon optimized genes were cloned into expression vectors using restriction sites available in the expression vectors. The sequence of genes was confirmed using gene-specific primers. The final constructs were then transfected to the appropriate cell-lines and bulk pools or nano-pools were created using the appropriate selection markers for respective platform. 
Towards Excellence: An Indexed, Refereed \& Peer Reviewed Journal of Higher Education / Shailendra Gaur, Kinjal Bhadresha, Baldev Patel, Meenu Saraf, Rakesh Rawal / Page 143-165

Selection of nano-pools for fed-batch experiment: After the nano-pools/bulk-pools have recovered the stringent selection process, batch mode experiment was conducted to select the top 2 nano-pools for each platform technology for each molecule. Batch mode experiments were performed at 6 well-plate or T-25 stage in the same medium which was used for scaling up. Expression (titre) of batch samples were evaluated using molecule specific sandwich ELISA or Protein A HPLC method (data not shown). The top two nano-pools of each technology were further scaled up to shake-flasks and evaluated in a fed batch experiment. Selected pools were then evaluated at a fed batch level across different technologies (Fig: 4-6). Since mAb1 was the first molecule which was evaluated, and nano-pools were not tried till then, bulk pools were developed post transfection and were used for evaluation of technologies (Fig: 3)

\section{Transfection}

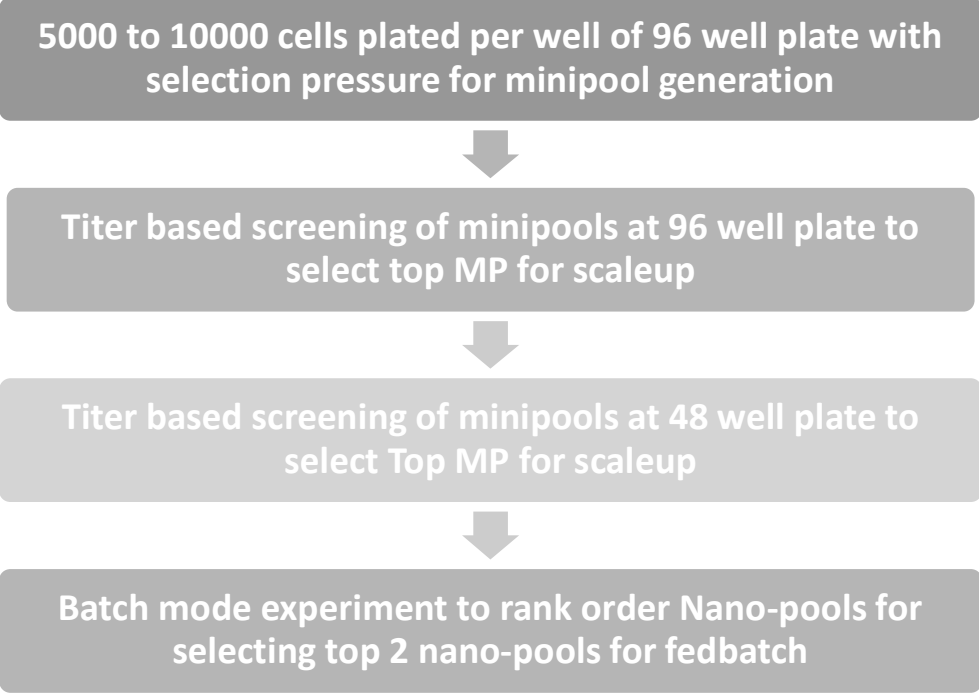

Top 2 nano-pool for each technology were used for fed-batch experiment for comparison purpose

Figure 2: Flow of nano-pool generation and fed-batch evaluation. For mAb1, bulk pools were developed and above mentioned flow was not adapted. 
Towards Excellence: An Indexed, Refereed \& Peer Reviewed Journal of Higher Education / Shailendra Gaur, Kinjal Bhadresha, Baldev Patel, Meenu Saraf, Rakesh Rawal / Page 143-165

Comparison of technologies:

During the early stage of evaluation (mAb1) we used bulk pools to compare between the technologies but the way bulk pools are generated (huge number of cells put together for selection) it may not provide enough heterogeneity in the clones. Thus, to segregate them efficiently nano-pool approach was adapted however, since generating nano-pools gave us a better way of segregating high producers with minimum heterogeneity in single pool thus, we went ahead to generate nano-pools for all the future molecules and selected best nano-pools in terms of titer. This ways we had a stringent screening before selecting our best nano-pool for fed batch evaluation.

To compare the fold change in expression and specific productivity, Technology-1 system was considered as "control" for our lab and relative expression was measured for other platforms against it.

\section{Comparison} of $\quad \mathrm{mAb} 1$ bulk-pools by fed batch experiments

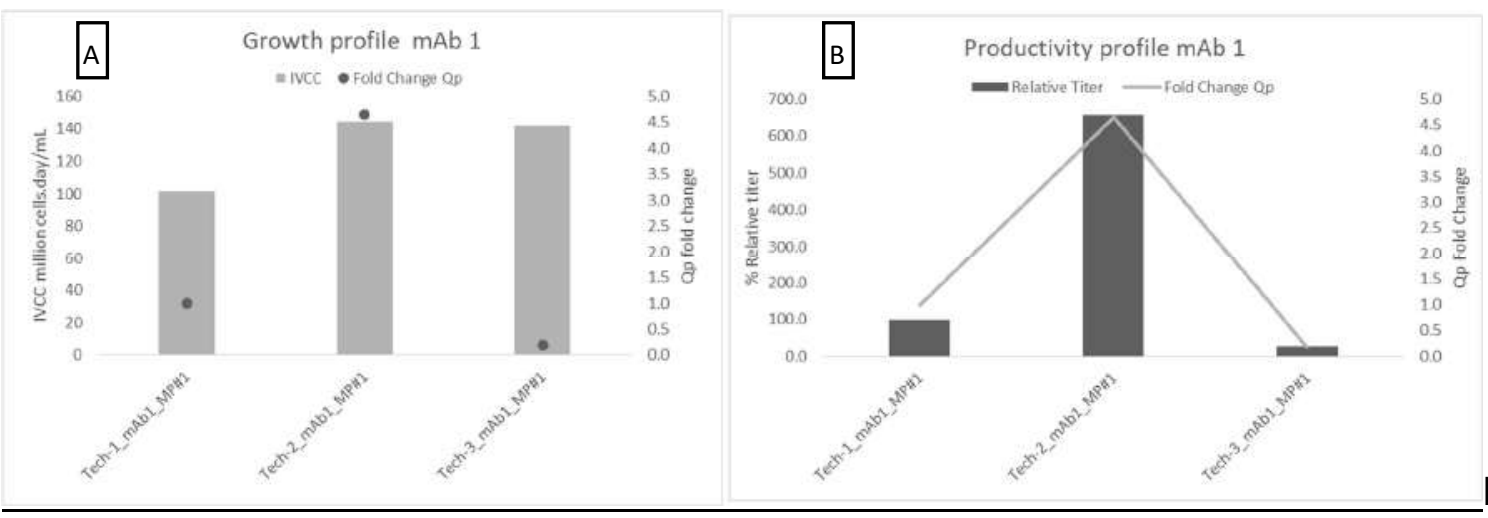

Figure

3: Fed-batch profile of mAb1 molecule. Figure 3[A] depicts growth (IVCC) and specific productivity (Qp) profile, while figure 3[B] shows relative expression and fold change in Qp as compared to tech-1. Technology 1 platform was used as control to evaluate fold change expression of the other two platform. 
Towards Excellence: An Indexed, Refereed \& Peer Reviewed Journal of Higher Education / Shailendra Gaur, Kinjal Bhadresha, Baldev Patel, Meenu Saraf, Rakesh Rawal / Page 143-165

Bulk pools of all the technologies for mAb1 were evaluated in standard fed-batch conditions. All the pools were evaluated in similar conditions of media and physical parameters. Technology-1 showed lesser growth (IVCC) as compared to other two platforms. While the Specific productivity of technology-3 was least even though the growth was on higher side, reflecting very poor expression per cell. Technology-2 platform was much better in terms of productivity of mAb1, even though there was no great difference between growth profiles but there was huge difference in expression. As compared to technology-1 platform, technology-2 platform's expression was almost 6 folds high while as compared to technology-3 platform it was about 10 folds better both in relative expression and specific productivity.

As it was a bulk pool the results are actually average of very heterogeneous population of cells as there was no segregation as such. Thus, going ahead nano-pool approach was adapted to achieve efficient segregation and selection of high expressing cells.

\section{Comparison of mAb2 nano-pools by fed batch experiments}

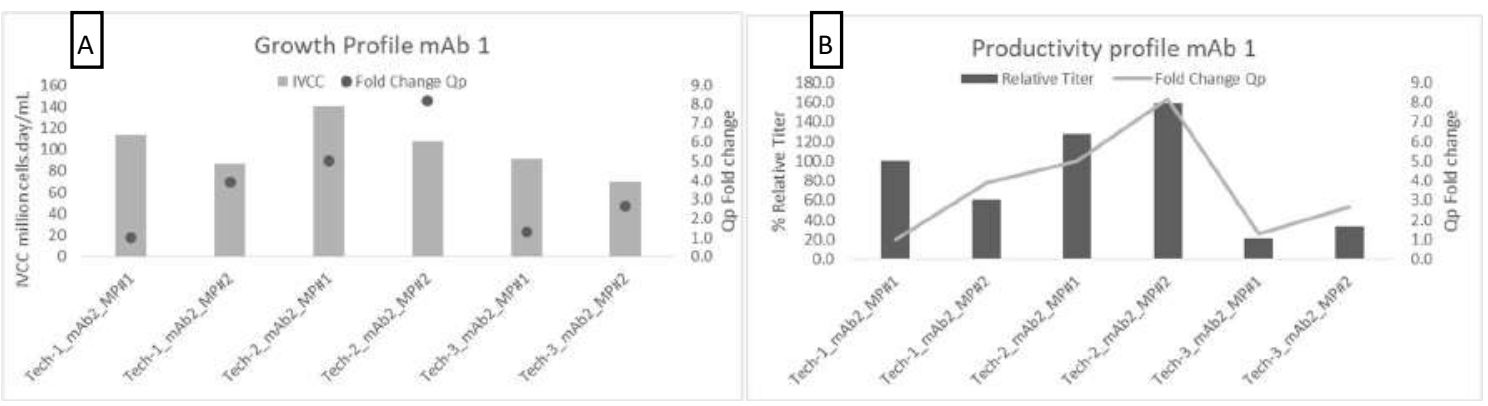

Figure 4: Fed-batch profile of mAb2 molecule. Figure 4[A] depicts growth (IVCC) and specific productivity (Qp) profile of top two nano-pools of each platform, while figure 4[B] shows relative expression and fold change in Qp as compared to tech-1 platform.

Top two selected nano-pools from each technology platform were picked for comparison study for mAb2 molecule (Fig: 4). The nano-pools of technology-2 achieved higher titre than the nano-pools of technology-1 platform. Nano-pools generated using technology-3 platform 
Towards Excellence: An Indexed, Refereed \& Peer Reviewed Journal of Higher Education / Shailendra Gaur, Kinjal Bhadresha, Baldev Patel, Meenu Saraf, Rakesh Rawal / Page 143-165

had the lowest expression as well as Qp. The results were in line to mAb1 expression profile. The highest relative expression of top nano-pool of technology- 2 was about $160 \%$ as compared to technology-1 and close to $400 \%$ as compared to Sigma. Similarly, Qp fold change was close to 2 folds in technology-2 as compared to technology- 1 and 3 folds as compared to technology3.

Thus, with both the mAb molecules we got similar trend where technology-2platform clearly outperformed other two platforms of, in both bulk-pool and as well as nano-pool strategy.

\section{$\underline{\text { Comparison of non-mAb1 nano-pools by fed batch experiments }}$}

After evaluating all three mammalian expression platforms with two mAb molecules, where technology-2 platform has come as clear winner, we initiated a non-mAb molecule for evaluation of all the platforms. We selected one of the well-known serine protease for this evaluation. Similar to development of mAb molecules, nano-pools were developed for nonmAb molecule and top two nano-pools of each of three platforms were subjected to fed-batch analysis for a head to head comparison.

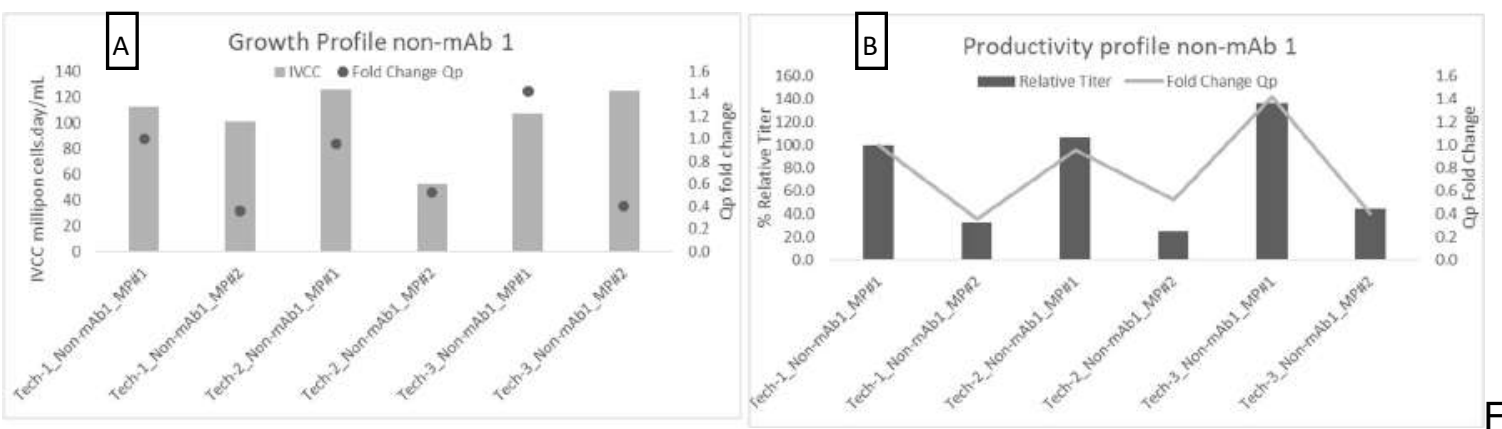

Figure

5: Fed-batch profile of non-mAb serine protease molecule. Figure 5[A] depicts growth (IVCC) and specific productivity (Qp) profile of top two nano-pools of each platform, while figure $5[B]$ shows relative expression and fold change in $Q p$ as compared to Invitrogen platform. 
Towards Excellence: An Indexed, Refereed \& Peer Reviewed Journal of Higher Education / Shailendra Gaur, Kinjal Bhadresha, Baldev Patel, Meenu Saraf, Rakesh Rawal / Page 143-165

Although tech-2 platform performed better than the other two platform in mAbs, we did not see similar trend in non-mab1 case. The top nano-pools of all three technologies were nearly close, with in an expression variation of about 30 percent and there was no clear winner here. Similar were the Qp profiles with a fold change difference within 0.3 folds. As far as ranking is concern technology-3 gave best expression which was $30 \%$ higher than technology-1, while tech-2 and tech-1 top nano-pools were almost similar. It was also observed that the difference between first and second nano-pool in all the technologies was very significant which was not observed in earlier cases.

\section{Comparison of non-mAb2 nano-pools by fed batch experiments}

Furthermore, we evaluated one more non-mAb molecule which was even more sensitive, unstable and hard to express protein of high molecular weight. Additionally, due to time constrain and results of previous studies (mAb molecules) we did not develop nano-pools for non-mAb 2 molecule in technology-3 platform as in most of the cases it was inferior to other two platforms (by then results for non-mAb1 study were not available). Considering the sensitivity to degradation for the tested molecule, running a long fed batch experiment was particularly tricky. With a little process optimization, we decided on running a shorter fed-batch experiment of 7 days with a higher seeding density to begin with. Although, the titres and Qp were lower for this molecule, nano-pools generated using technology-1 gave twice the expression as compared to nano-pools generated using technology-2 as shown in figure 6 .

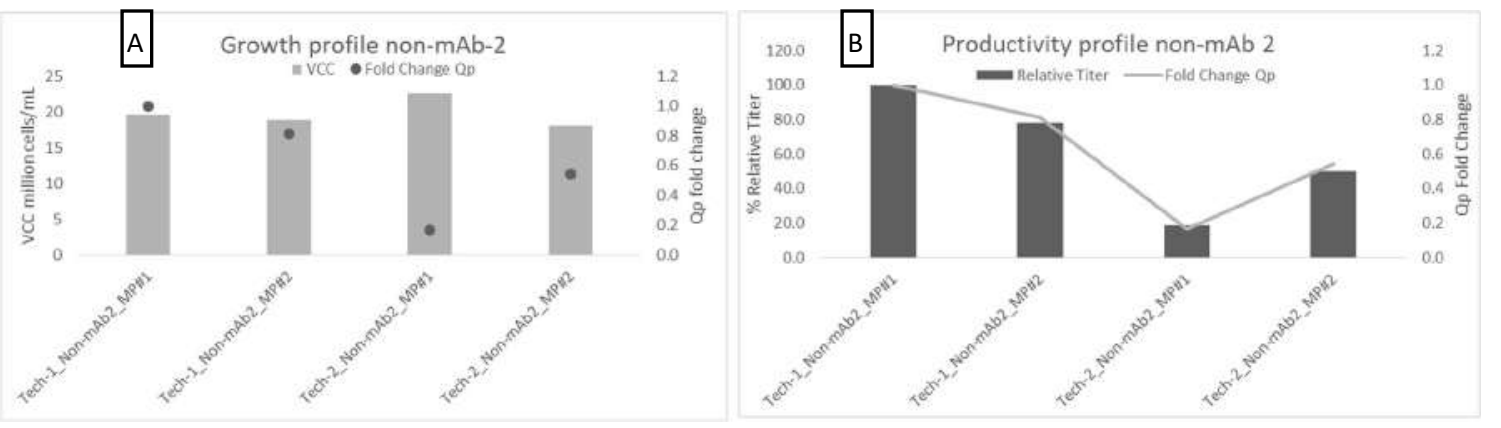


Towards Excellence: An Indexed, Refereed \& Peer Reviewed Journal of Higher Education /

Shailendra Gaur, Kinjal Bhadresha, Baldev Patel, Meenu Saraf, Rakesh Rawal / Page 143-165

Figure 6: Modified fed-batch profile of non-mAb molecule. Figure 6[A] depicts growth (peak VCC) and normalised titer profile of top two nano-pools of both the platforms, while figure $6[B]$ shows relative expression and fold change in normalised titer as compared to Invitrogen platform.

As the above batch was not taken as per standard fed-batch and cells were grown only for a limited period of 7 days thus daily monitoring of cell culture parameters were not done and IVCC and Qp was not calculated while a normalized titer was calculated per million VCC and is represented. The data represented here for growth profile is peak viable cell count (VCC) and the titer obtained on day 7 was divided with peak VCC value to normalised the titer, so that results are not biased towards high cell counts of specific nano-pool. In the above figure 6 we observed that growth profile was similar for both the technologies, but there was significant difference in terms of expression and normalised titers. Both the nano-pools of technology-1 platform performed significantly better than technology-2 platform. The expression was about $50 \%$ lower with technology-2 as compared to technology- 1 and similarly normalised titer of technology-1 was twice as compared to technology-2 platform.

\section{Discussion}

The recent advancement in the field of recombinant therapeutics can be attributed to the rapid advances in technology post publication of the $\mathrm{CHO}$ genome (Hernandez-Lopez et al. 2017; Hilliard and Lee 2020). The switch-over from chemical drugs to protein-based

therapies has boosted the demand for these biologics. Since mammalian biologics form a large segment of this market, development of stable cell lines expressing these recombinant proteins forms the starting point for this commercialization (Clarke and Compton 2008; Mortensen and Kingston 2009). The levels of protein expression by these cell lines often impact the final product cost and profits. Hence higher protein expression will directly translate to higher profits. 
Towards Excellence: An Indexed, Refereed \& Peer Reviewed Journal of Higher Education /

Shailendra Gaur, Kinjal Bhadresha, Baldev Patel, Meenu Saraf, Rakesh Rawal / Page 143-165

Generating these stable cell lines, however does create a bottle-neck for biopharmaceutical industries. Numerous service providers have stepped in to fill this gap and ease out the clone development process by providing platform technology solutions (Table 1). Most of these technologies are based on auxotrophic selection of transfectants. These technologies may be broadly divided into two types of auxotrophic selections: DHFR (Dihydrofolate reductase) based and GS (Glutamine synthetase) based. A few other platform technologies use vector and cell biology to improve expression. These technologies may exploit genetic elements of the cell which alter the local environment of the DNA to increase the expression like S/MAR or UCOE (Kim et al. 2004; Williams and Cranenburgh 2008).

We have evaluated 3 such platform technologies using $2 \mathrm{mAb}$ and 2 non-mAb molecules. The main aim of our study was to determine the most suitable platform technology for production of mAbs and non-mAbs out of the three. From the data we have generated, we have observed that the UCOE based technology-2 platform has shown higher productivity in cell lines expressing mAb molecules. The expression of mAbs using UCOE platform was 3-7 fold higher than the closest competitor. These results were similar to what have been reported by Neville et al. They showed $>10$ fold increase in mAb expression in bulk pools developed using Rsp3 UCOE vector (Neville et al. 2017). UCOE is known to help in site-of-integration independent transgene expression and hence may enhance the expression of protein in cells with uniform copy number. It is also known to confer stability to the clones expressing the protein. Betts et al. (Betts et al. 2015) also showed an enhanced expression of GFP using

UCOE expression platform as compared to non-UCOE based cell-lines without DHFR based amplification. We have evaluated all three technologies at a basal level without any amplification. Although, our results indicated higher expression of mAbs in pools transfected with UCOE vector, the results have been generated without any amplification process. 
Towards Excellence: An Indexed, Refereed \& Peer Reviewed Journal of Higher Education /

Shailendra Gaur, Kinjal Bhadresha, Baldev Patel, Meenu Saraf, Rakesh Rawal / Page 143-165

Furthermore DHFR based and GS based technologies offer enhancement in protein production using MTX and MSX for amplification respectively. While UCOE vector does not offer this enhancement. A further enhancement in fold expression of mAbs may be possible with the other technologies which has not been covered in our scope of study.

The results observed in the technology evaluation for non-mAb molecules were nonconclusive. In one case, where expressions were comparable in all platforms while in another case, Dhfr based platform was found superior to UCOE platform. Although, GS based platform gave marginally higher expression as compared to DHFR based platform or UCOE based platform in pools expressing non-mAb 1, we were unable to evaluate all three platforms for non-mAb 2. Expression of non-mAbs is much more complex as compared to mAbs molecules, with multiple post translational modifications and involvement of additional enzymes and cofactors. Hence, the expression of these proteins cannot be linearly correlated with copy number and thus we had distinct results in case of mAb molecules with UCOE based platform being a clear winner but the results in case of non-mAb molecules showed more variability.

Thus, based on the data we generated we conclude that for monoclonal antibody expression, UCOE based platforms can be used very efficiently, as it gives much better volumetric and per cell productivity. But, for non-mAb molecules we still need to look for various platforms before selecting one due to highly complex characteristics of non-mAb molecules.

The assessment made is purely based on the data observed for the particular molecules in our laboratory conditions, and the results may vary with different molecules in different set of conditions. 
Towards Excellence: An Indexed, Refereed \& Peer Reviewed Journal of Higher Education / Shailendra Gaur, Kinjal Bhadresha, Baldev Patel, Meenu Saraf, Rakesh Rawal / Page 143-165

Dec, 2020. VOL.12. ISSUE NO. $5 \quad$ https://hrdc.gujaratuniversity.ac.in/Publication $\quad$ Page | 160 
Towards Excellence: An Indexed, Refereed \& Peer Reviewed Journal of Higher Education / Shailendra Gaur, Kinjal Bhadresha, Baldev Patel, Meenu Saraf, Rakesh Rawal / Page 143-165

\section{References}

1. Betts Z, Croxford AS, Dickson AJ (2015) Evaluating the interaction between UCOE and DHFR-linked amplification and stability of recombinant protein expression. Biotechnol Prog 31:1014-1025. https://doi.org/10.1002/btpr.2083

2. Birch JR, Racher AJ (2006) Antibody production. Adv Drug Deliv Rev 58:671-685. https://doi.org/10.1016/j.addr.2005.12.006

3. Buchsteiner M, Quek LE, Gray P, Nielsen LK (2018) Improving culture performance and antibody production in $\mathrm{CHO}$ cell culture processes by reducing the Warburg effect. Biotechnol Bioeng 115:2315-2327. https://doi.org/10.1002/bit.26724

4. Butler M, Meneses-Acosta A (2012) Recent advances in technology supporting biopharmaceutical production from mammalian cells. Appl. Microbiol. Biotechnol. 96:885894

5. Carroll D (2011) Genome engineering with zinc-finger nucleases. Genetics 188:773-782. https://doi.org/10.1534/genetics.111.131433

6. Clarke H, Compton B (2008) Comparing Mammalian Expression Systems The First RateLimiting Step in Making Products for Clinical Testing. BioProcess Int 6:

7. Dharshanan S, Chong H, Cheah SH, Zamrod Z (2014) Stable expression of H1C2 monoclonal antibody in NSO and $\mathrm{CHO}$ cells using pFUSE and UCOE expression system. Cytotechnology 66:625-633. https://doi.org/10.1007/s10616-013-9615-x

8. Fan L, Kadura I, Krebs LE, et al (2012) Improving the efficiency of CHO cell line generation using glutamine synthetase gene knockout cells. Biotechnol Bioeng 109:1007-1015. https://doi.org/10.1002/bit.24365

9. Fischer S, Handrick R, Otte K (2015) The art of $\mathrm{CHO}$ cell engineering: A comprehensive retrospect and future perspectives. Biotechnol. Adv. 33:1878-1896 
Towards Excellence: An Indexed, Refereed \& Peer Reviewed Journal of Higher Education / Shailendra Gaur, Kinjal Bhadresha, Baldev Patel, Meenu Saraf, Rakesh Rawal / Page 143-165

10. Gupta SK, Shukla P (2017) Sophisticated cloning, fermentation, and purification technologies for an enhanced therapeutic protein production: A review. Front Pharmacol 8:1-17. https://doi.org/10.3389/fphar.2017.00419

11. Hernandez-Lopez I, Auer N, Grillari J, et al (2017) Transcriptomic changes in CHO cells after adaptation to suspension growth in protein-free medium analysed by a species-specific microarray. J Biotechnol 257:. https://doi.org/10.1016/j.jbiotec.2017.03.012

12. Hilliard W, Lee KH (2020) Systematic Identification of Safe Harbor Regions in the $\mathrm{CHO}$ genome through a Comprehensive Epigenome Analysis. Biotechnol Bioeng. https://doi.org/10.1002/bit.27599

13. Jazayeri SH, Amiri-Yekta A, Bahrami S, et al (2018) Vector and Cell Line Engineering Technologies Toward Recombinant Protein Expression in Mammalian Cell Lines. Appl Biochem Biotechnol 185:986-1003. https://doi.org/10.1007/s12010-017-2689-8

14. Kalwy S, Porter A, Watson C, Gay R (2000) Rapid Selection of High Yielding Gs-Cho Cell Lines Using the Gs Expression System in a Protein-Free, Fully Chemically Defined, Animal Component-Free Process. Eur J Immunogenet 300

15. Kim JM, Kim JS, Park DH, et al (2004) Improved recombinant gene expression in $\mathrm{CHO}$ cells using matrix attachment regions. J Biotechnol 107:95-105. https://doi.org/10.1016/j.jbiotec.2003.09.015

16. Kim JY, Kim YG, Lee GM (2012) CHO cells in biotechnology for production of recombinant proteins: Current state and further potential. Appl. Microbiol. Biotechnol. 93:917-930

17. Lai T, Yang Y, Ng SK (2013) Advances in mammalian cell line development technologies for recombinant protein production. Pharmaceuticals 6:579-603

18. Lazar GA, Dang W, Karki S, et al (2006) Engineered antibody Fc variants with enhanced effector function. Proc Natl Acad Sci U S A 103:4005-4010. https://doi.org/10.1073/pnas.0508123103 
Towards Excellence: An Indexed, Refereed \& Peer Reviewed Journal of Higher Education / Shailendra Gaur, Kinjal Bhadresha, Baldev Patel, Meenu Saraf, Rakesh Rawal / Page 143-165

19. Lin PC, Chan KF, Kiess IA, et al (2019) Attenuated glutamine synthetase as a selection marker in $\mathrm{CHO}$ cells to efficiently isolate highly productive stable cells for the production of antibodies and other biologics. MAbs 11:965-976. https://doi.org/10.1080/19420862.2019.1612690

20. Luchese MD, Lopes dos Santos M, Garbuio A, et al (2018) A new CHO (Chinese hamster ovary)-derived cell line expressing anti-TNFa monoclonal antibody with biosimilar potential. Immunol Res 66:392-405. https://doi.org/10.1007/s12026-018-8997-4

21. Mortensen RM, Kingston RE (2009) Selection of transfected mammalian cells. Curr. Protoc. Mol. Biol.

22. Naso MF, Tam SH, Scallon BJ, Raju TS (2010) Engineering host cell lines to reduce terminal sialylation of secreted antibodies. MAbs 2:519-527. https://doi.org/10.4161/mabs.2.5.13078

23. Neville JJ, Orlando J, Mann K, et al (2017) Ubiquitous Chromatin-opening Elements (UCOEs): Applications in biomanufacturing and gene therapy. Biotechnol Adv 35:557-564. https://doi.org/10.1016/j.biotechadv.2017.05.004

24. Pfaff N, Lachmann N, Ackermann M, et al (2013) A ubiquitous chromatin opening element prevents transgene silencing in pluripotent stem cells and their differentiated progeny. Stem Cells 31:488-499. https://doi.org/10.1002/stem.1316

25. Pohlscheidt M, Kiss R, Gottschalk U (2018) An introduction to „Recent Trends in the Biotechnology Industry: Development and Manufacturing of Recombinant Antibodies and Proteins“. In: Advances in Biochemical Engineering/Biotechnology. Springer Science and Business Media Deutschland GmbH, pp 1-8

26. Rocha-Pizaña M del R, Ascencio-Favela G, Soto-García BM, et al (2017) Evaluation of changes in promoters, use of UCOES and chain order to improve the antibody production in $\mathrm{CHO}$ cells. Protein Expr Purif 132:108-115. https://doi.org/10.1016/j.pep.2017.01.014

27. Romanova N, Noll T (2018) Engineered and Natural Promoters and Chromatin-Modifying 
Towards Excellence: An Indexed, Refereed \& Peer Reviewed Journal of Higher Education / Shailendra Gaur, Kinjal Bhadresha, Baldev Patel, Meenu Saraf, Rakesh Rawal / Page 143-165

Elements for Recombinant Protein Expression in $\mathrm{CHO}$ Cells. Biotechnol J 13:. https://doi.org/10.1002/biot.201700232

28. Siew A (2016) Expression systems for the development of biosimilars. BioPharm Int 29:2829

29. Tripathi NK, Shrivastava A (2019) Recent Developments in Bioprocessing of Recombinant Proteins: Expression Hosts and Process Development. Front. Bioeng. Biotechnol. 7

30. Williams S, Cranenburgh R (2008) Improving clone production for increased protein yield from mammalian cell lines. Innov Pharm Technol 52-56

31. Xu N, Ou J, Gilani AK (Al), et al (2015) High-level expression of recombinant IgG1 by $\mathrm{CHO}$ K1 platform. Front Chem Sci Eng 9:376-380. https://doi.org/10.1007/s11705-015-1531-5

32. Zhang F, Frost AR, Blundell MP, et al (2010) A Ubiquitous Chromatin Opening Element (UCOE) confers resistance to DNA methylation-mediated silencing of lentiviral vectors. Mol Ther 18:1640-1649. https://doi.org/10.1038/mt.2010.132

\title{
Shailendra Gaur
}

Department of Microbiology \& Biotechnology, University School of Sciences, Gujarat University, Ahmedabad seeshail@gmail.com

\author{
\& \\ Kinjal Bhadresha \\ Department of Life Science, University School of Sciences, Gujarat University, \\ Ahmedabad \\ kinjalbhadresha@outlook.com \\ \& \\ Baldev Patel \\ Department of Microbiology \& Biotechnology, University School of Sciences, \\ Gujarat \\ University, Ahmedabad patelbaldev56@yahoo.in
}


Towards Excellence: An Indexed, Refereed \& Peer Reviewed Journal of Higher Education / Shailendra Gaur, Kinjal Bhadresha, Baldev Patel, Meenu Saraf, Rakesh Rawal / Page 143-165

Meenu Saraf

Department of Microbiology \& Biotechnology, University School of Sciences, Gujarat

University, Ahmedabad msaraf@guajaratuniversity.ac.in

\&

\section{Rakesh Rawal}

Department of Life Science, University School of Sciences, Gujarat University, Ahmedabad

rakeshmrawal@gmail.com 